\title{
Study on the Causes of Male Preschool Teachers' Absence and Countermeasures
}

\author{
Yan CHEN \\ School of Primary Education, Zaozhuang College \\ Zaozhuang, 277300, Shandong
}

\begin{abstract}
The strong will and masculine quality of male kindergarten teachers have a subtle influence on the healthy growth of children. This paper investigates the number of male teachers in kindergartens in Zaozhuang area and analyzes the reasons for the lack of male teachers in kindergartens. The following factors behind the fact are found: male kindergarten teachers lack interest and enthusiasm for preschool education; they are influenced and bound by traditional social concepts, and hold that this profession means low social identity; the profession provides poor social treatment and low wages; the profession lacks government support; the training mechanism of normal colleges is not perfect. Based on the above factors, this paper proposes a serious of countermeasures for the shortage of male kindergarten teachers and provides solutions.
\end{abstract}

Keywords-Male kindergarten teachers; Reasons for shortage; Absence; Solutions

\section{INTRODUCTION}

According to psychological research, the early childhood stage is the key period of personality and character development in a person's life, during which children learn mainly through imitation. However, in the current society, the feminization of kindergartens has become a common phenomenon. Children have long been in the educational atmosphere of female teachers, while boys imitate female teachers, and there will be a partial feminization. Nowadays, young boys generally lack the spirit and ability to be independent, strong and adventurous. Therefore, kindergartens call for more male teachers to join the cause of preschool education, and children need " masculine" education.

Internationally, the proportion of male kindergarten teachers in Holland and Australia is about $6 \%$, that of Japanese kindergarten teachers is about $7 \%$, and that of American kindergarten teachers is about $10 \%$. According to the survey, the total number of kindergarten teachers in China is about 1 million, but the number of male preschool teachers ( teaching ) is less than 10,000, and the proportion of male preschool teachers is only $1 \%$. In contrast, there is a big gap between China and developed countries. [1](P180) Through investigation, it is found that there is also a situation in Zaozhuang where kindergarten female preschool teachers dominate the whole country, with a male-to-female ratio of about 1: 105. Preschool experts, directors and parents believe that the lack of male preschool teachers in kindergartens has a negative impact on children's personality development and psychological growth. Therefore, there is an urgent need for male kindergarten teachers, and relevant specialties in normal colleges have begun to introduce corresponding policies to attract male students. However, many male kindergarten teachers leave their jobs or change professions due to various reasons in the process of learning their profession or employment, which is not conducive to the development of national kindergartens and the growth of young children. Therefore, it is of practical significance for the better development of preschool education in our country to find out the reasons for the lack of male kindergarten teachers and put forward countermeasures and methods.

\section{THE LACK OF MALE KINDERGARTEN TEACHERS DIFFICULT ANALYSIS}

Through the analysis of 60 teachers and students of preschool education major in Zaozhuang area in the form of investigation, interview, questionnaire and observation, it is found that the main difficulties affecting the lack of male kindergarten teachers in Zaozhuang area are:

\section{A. Difficult source of students.}

Although there are no gender restrictions on the enrollment of preschool education majors at the undergraduate level and the scores are lower than those of other majors, few boys enter for this major. The other five-year colleges also began to recruit boys, but most of the boys who entered for the exam were hopeless, with poor grades and low stability. They didn't know anything about their major or were not interested in it, but were sent to school by their parents, so they were engaged in more other professions when they were employed. According to the survey, in recent years, the male preschool education graduates from Zaozhuang College are very popular. However, the proportion of male students who come to the interview every year and finally apply is about 1: 25 .

\section{B. Leaving difficulties behind.}

There were fewer boys applying for pre-school major. At the undergraduate level, male students of this major will request to change their major or use it as a springboard to obtain graduate students of other majors. Most of the boys at the junior college level were forced to go to school by their parents, and they were not interested in their major. They dropped out of school because they lacked advantages compared with girls in the learning process, or went to 
primary school to teach after graduation. Shandong Normal University enrolled 11 boys in 2001, and only one was actually engaged in kindergarten education and teaching.

\section{Academic difficulties}

In the process of learning pre-school majors, boys have difficulties in learning many professional skills such as dance, piano and manual skills, and are at a disadvantage, which has hit boys hard. In addition, in the study of professional theory, boys lack interest and motivation due to factors such as students' age and lack of practice. According to the survey, the scores of boys majoring in primary education in Zaozhuang College are basically at the middle and lower levels in the class, and the percentage of winning prizes in hand-made competitions, dance competitions and Chinese poetry recitation competitions in the school is significantly lower than that of girls.

\section{The interpersonal relationship is difficult}

In pre-school education, boys and girls show a phenomenon of yin, sheng, yang and decline. girls are mostly class leaders and leaders. they are organizers of classes and activities. under such circumstances, boys feel depressed, and they gradually become sensitive, self - abased, bored, feminine and lack of a sense of accomplishment. The communication between male and female students is less, which is not conducive to the formation of a collective sense of belonging and professional identity for boys.

\section{E. Difficult to get good job after graduation}

Although many kindergartens compete for male kindergarten teachers, most of them are private ones with low wages and unstable conditions. Only a few public kindergartens recruit kindergarten teachers, but the number of places is very small.

\section{THE CAUSE OF THE DIFFICULTY}

\section{A. Lack of interest and enthusiasm in preschool teaching}

According to a survey among boys in Zaozhuang College in 2013 and 2014, $82 \%$ of boys did not voluntarily choose a major, most of them did not come to school with interest, but were forced to do so by their parents. They camped temporarily with the mentality of watching and playing, and some chose to drop out of school within a year. There are also some boys who said that after getting along with their children in the internship, their innocence also infected them, but why did male kindergarten teachers choose to leave after they really entered the kindergarten, and why did they leave?

\section{B. Affected and bound by traditional social concepts, and hold that it means low social identity}

The social environment is an important factor that causes boys to leave. Influenced by traditional social concepts, most people think that preschool teachers do not need any skills to " see children" and ordinary people can be competent after a short period of training. As a man, he should bear the heavy burden of the family. He is often laughed at by others for taking up the profession of bringing children. At the same time, some titles such as "Male Uncle" also hurt the self-esteem of male kindergarten teachers. Misunderstandings and prejudices make male kindergarten teachers have no courage to enter kindergarten. At the same time, some parents think that men are not careful and patient in taking care of their children, and that it is not convenient to take care of the little girl and are more willing to choose the class of female teachers. Therefore, male kindergarten teachers feel distrustful and frustrated. Because of this, people look at men engaged in preschool education with colored glasses and regard them as unsuccessful men, thus greatly affecting their enthusiasm and interest in work.

\section{Poor social treatment and low wages}

This is a direct factor for male kindergarten teachers to choose to leave. Although the kindergarten needs male preschool education urgently, it is no different from female teachers in terms of salary and pay, and bears more family burdens than female teachers. According to the survey, the monthly salary of kindergarten teachers in Zaozhuang district is only about 1200 yuan ( private ) on average, and sometimes they are not paid in time. However, in government units directly under the government and public kindergartens, teachers' salaries reach about 2600 - 3000 ( teachers with establishment ) and those without establishment are about 1500. However, in some rural kindergartens in Zaozhuang, wages are lower than those in 800 yuan. In the family, men bear greater economic responsibility, and too little or unstable income affects their marital status and family status. Under various circumstances, male teachers are forced to choose other professions or take part in postgraduate examinations, thus giving them more choice.

\section{The support of the government is not enough}

Government departments do not pay too much attention to boys in the recruitment examination every year, but only require relevant professional qualifications and vocational qualification certificates. Male and female students compete, boys are at a disadvantage and often lose out in skills assessment and interview, and the number of kindergarten teachers recruited every year is very small. Taking Zaozhuang as an example, Zaozhuang started to recruit kindergarten teachers in 2007, only one in 2007, 2008 and 2009, 10 in 2010, 3 in 2011 and 2012, 5 in 2014, and no recruitment in 2015, which is very small compared with other professional recruitment. In Yicheng District of Zaozhuang City, kindergarten teachers have not been recruited for more than 10 years. 


\section{E. The training mechanism of normal colleges is not perfect}

There is a big gender gap in normal colleges and universities, and the ratio of male and female students in preschool education is seriously unbalanced. Take the primary education college of Zaozhuang University as an example, there are 16 male students among 572 kindergarten teachers. In terms of curriculum setting, piano, dance and other courses offered are more suitable for girls and few for boys. Moreover, there are more female teachers in this major, and they prefer girls in teaching methods and methods. In the teaching mode, because too few boys may ignore the characteristics of boys and adopt a more suitable mode for girls. In terms of teaching costs, it is impossible for schools to adopt a separate teaching mode for a very small number of boys. Not only that, many boys who originally chose the preschool education major have difficulty in learning or do not adapt to it during the learning process. They are confused about the preschool education major and drop out of school, which makes the already small number of boys even rarer.

\section{Countermeasures to Solve Problems}

\section{A. Variety of measures to change traditional ideas and enhance interest}

1) Strengthen professional education and raise awareness and interest

In the process of professional education, on the one hand, we can use the power of example, for example, to introduce famous pre-school education experts at home and abroad, especially famous pre-school education experts in China: Chen Heqin, Zhang Xuemen, Zhang Zonglin, Tao Xingzhi and other pre-school education predecessors, who have written a strong story in the history of pre-school education in China. On the other hand, we can use various forms to increase students' awareness: inviting male kindergarten teachers who have graduated to talk, conducting lectures by kindergarten directors and inviting successful pre-school education outside school to carry out professional education, thus increasing their recognition, confidence and love for the profession. At the same time, male kindergarten teachers themselves should have correct working concepts and make timely adjustments to some wrong traditional ideas.

2) Use public opinion to gain professional recognition.

There is prejudice against male teachers in society, which leads to the departure of male teachers and the instability of male teachers. We must establish correct public opinion. Male preschool education plays an important role in the growth of young children. Social members should change their ideas, treat male kindergarten teachers correctly and rationally, and give them full respect and affirmation. Parents should also eliminate misunderstanding about male kindergarten teachers and recognize their work. At the same time, we have strengthened publicity efforts in the society, such as the parent-child program " Daddy's Back" and "Where Dad Goes" which have recently aroused heated discussion in the society, showing the importance of male roles to children's growth from the side.

\section{3) Calm down and be positive and optimistic}

The development of everything needs a process. Male teachers receive too much attention and favor in the recruitment process, but there may be a certain gap between the actual work and the attention they think they receive. Therefore, male teachers should be calm and optimistic about their career and work, and have a correct role orientation for themselves. I believe they can do the best. Huang Chengxiang, a teacher of Mengshi class in Zaozhuang Experimental Kindergarten, graduated from the School of Primary Education of Zaozhuang College and is a graduate of Grade 2008 primary education of the College. He joined the experimental kindergarten in 2012 and has been working until now, working in Mengshi teaching and kindergarten. He said: " I like this job very much. I feel pure and simple happiness from my children. The children in our class like me very much. I am proud and proud to see the smiling faces of the children. I don't think it is different from a female teacher at work. I firmly believe that I will continue to work. "Seeing his confident face, I believe he will become an excellent preschool teacher and will have his name among the outstanding personnel in Zaozhuang preschool education industry.

\section{B. Change the management mode and mechanism and gradually increase the salary}

1) The government and education authorities should use policies to attract male kindergarten teachers to join, thus changing the phenomenon that there are many male and female kindergarten teachers

Teachers' colleges have increased the number of male students by offering full scholarships or free tuition fees to attract outstanding male students to apply for this major. Formulate policies in favor of boys in the recruitment examination: restrict boys or exempt boys from written tests so that more boys can choose to enter kindergarten. For example, L City stipulated in the charter for recruiting kindergarten teachers that male students in full-time ordinary colleges and universities with pre-school education of junior college degree can enter the interview directly and be exempted from written examination. Such a policy attracts a large number of male kindergarten teachers to enter the exam.

2) Kindergarten improves treatment and provides space and platform for development

For kindergartens, male kindergarten teachers are rare and precious. Since the introduction, will stay. Therefore, high salary and high fortune are the best way to retain male kindergarten teachers. A monthly allowance or a teaching reward for men engaged in preschool education will be given to improve their treatment so that male teachers can stay. For example, the salary of male teachers in experimental kindergarten in Zaozhuang Tengzhou City is $20 \%$ higher than that of female teachers, and there are now five teachers who have a strong affinity for children. Some parents specifically request male teachers to take their children with them. In addition, kindergartens should also create opportunities to provide space and platforms for the development of male kindergarten teachers so that they can have more sense of 
achievement and self-confidence and take root in the cause of preschool education for a long time.

\section{Reform the training mechanism of normal colleges and universities and teach students in accordance with their aptitude}

1) Considering the characteristics of boys, offering suitable courses

At present, although teachers colleges recruit different numbers of boys, they are the same as girls in the training mode, which is not conducive to the education and training of male kindergarten teachers, but will have the opposite effect. Therefore, in terms of curriculum arrangement, add courses suitable for boys and reflecting their advantages, such as adding martial arts, courseware making, gymnastics, science, etc. in dance teaching, arrange modern dance and jazz dance suitable for boys, and arrange male dance teachers to teach as much as possible.

2) Create a curriculum system adapted to the current kindergarten to make up for the disadvantage of girls

Preschool education is a major with strong skills and application, and it is a major to train excellent teachers for future kindergartens. Therefore, in the curriculum system, we should not only make close contact with the current kindergarten, adapt to the needs of the kindergarten, set up the corresponding curriculum system, and avoid the disconnection between theory and practice. We should also pay attention to the cultivation of boys, a special group, and cultivate boys' skills, which are different from girls' and make up for the disadvantages of female teachers. For example, boys have natural advantages in physical education. Only in this way can male and female teachers cooperate together, not compete, and play their respective advantages and learn from each other's strong points, can they create beautiful flowers in the fertile soil of preschool education.

\section{CONCLUSION}

The goal of early childhood education is to promote the harmonious development of children's body and mind, and male kindergarten teachers are indispensable in shaping children's healthy personality. Although the development status of male kindergarten teachers in the field of preschool education in China is good or good, it is scientific and objective to think about the development of preschool education from the new situation of international preschool education development in the new century and the height of China's modernization Regular choice. Only by continuing to encourage men to engage in early childhood education and vigorously developing the new team of male kindergarten teachers can children gain more lessons in a more harmonious and flexible educational environment, and can we promote our early childhood education from the edge of the educational stage to the center and realize unilateral education to complete education

\section{REFERENCES}

[1] Department of Development Planning, Ministry of Education. China Education Statistics Yearbook [M]. Beijing: People's Education Press, 2003. (In Chinese)

[2] Huang Qi. Research on the Entry and Adaptation of Male Kindergarten Teachers [D]. Nanjing: Nanjing Normal University, 2007. (In Chinese)

[3] Zheng Yile, Shi Wenxiu. Analysis of the loss of male kindergarten teachers and its countermeasures [J]. Preschool Education World, 2011, (1). (In Chinese)

[4] Yao Yakun. An interview study on the causes and countermeasures of the loss of male kindergarten teachers [J]. Theoretical Frontier, 2007, (6) (In Chinese)

[5] Liu Haiyuan. Analysis of the Causes and Management Countermeasures of Male Preschool Teachers' Absence - Taking Kashgar City as an Example [J]. Journal of Hubei University of Science and Technology, 2014, (6). (In Chinese)

[6] Gai Zhenhua. Infant growth requires male teachers to grow up - an inquiry into the reasons for the loss of male teachers in kindergartens $[\mathrm{J}]$ 2007, (1). (In Chinese)

[7] Yang Liyuan. Analysis of the Reasons for the Scarcity of Male Preschool Teachers [J]. Journal of Sichuan University of Arts and Sciences [J]. 2014,(11). (In Chinese)

[8] Hou Xiaoqian, Zhang Xiuchao. Attributions and countermeasures to the lack of resources for male kindergarten teachers in China [J]. Early Childhood Education (Educational Science), 2009, (10). (In Chinese)

[9] Liu Jianxia. Analysis of the Lack of "Masculine Education" in Kindergarten [J]. Journal of lishui university, 2013, (4). (In Chinese) 